\title{
Sex pheromones and aggressive behavior in male rats
}

\author{
GEORGE T. TAYLOR \\ University of Missouri-St. Louis, St. Louis, Missouri 63121
}

\begin{abstract}
Two experiments were performed to examine the relationships among the sexual cycle of the female, sex pheromones, and the agonistic behavior of male rats. Data suggest that the presence of an inaccessible sexually receptive female provokes increased intermale fighting. The present research investigated the possibility that a sex pheromone from the female mediates the change in male hostilities. In Experiment 1, a combination between-subject and within-subject design was used to expose half the males to the female by several sensory modalities. The other males were exposed to the female primarily by olfaction. In Experiment 2, a completely between-subject design was used to expose some males only to the soiled bedding of the female. The results suggest that olfaction is sufficient to increase the male's aggressiveness in the presence of an estrous female, although additional sensory input, such as the female's movements, may be necessary to produce the full aggression-inducing effect.
\end{abstract}

Agonistic behavior in mammals has often been observed to vary with the females' sexual cycle (Guhl, 1961). Observations of seasonally polyestrous and monestrous mammals suggest that fighting among males increases dramatically during the breeding season (Bermant \& Davidson, 1974, p. 73). Supporting evidence has come from studies with deermice, Peromyscus maniculatus (Healey, 1967; Sadlier, 1965), voles, Microtus ochrogaster and $M$. pennsylvanicus (Stehn, Richmond, \& Kollisch, 1976; Turner \& Iverson, 1973), gerbils, Meriones unguiculatus (Roper \& Polioudakis, 1977), feral rats, Rattus norvegicus (Barnett, Evans, \& Stoddart, 1968), and monkeys, Macaca mulatta (Wilson \& Boelkins, 1970).

The increased hostilities may be a direct consequence of seasonal environmental changes. For rats at least, the presence of a sexually receptive female provokes heightened aggressiveness among the males of the social group. In a series of laboratory studies with domesticated rats, Taylor $(1975,1976)$ found that both highly aggressive and subordinate males were more aggressive following exposure to an inaccessible estrous female. Since the male was prevented from physically interacting with the female by a screen, communication of the receptive state of the female may have been transmitted by a pheromone.

The present experiments were designed to investigate the pheromonal basis of the increased aggressiveness between males in the presence of an estrous female. The initial step was to demonstrate that the effect is

The research was supported by National Science Foundation Grant BNS76 18330. The author thanks Gary Burger for advice on the statistical analyses and Zuleyma Halpin for reading the manuscript. Requests for reprints should be sent to George $T$. Taylor, Department of Psychology, University of MissouriSt. Louis, St. Louis, Missouri 63121. indeed communicated by the pheromone. The experimental paradigm in the previous research (Taylor, $1975,1976)$ provided the male with an opportunity to use several sensory modalities to gain information about the female's sexual cycle. The first experiment exposed males to an inaccessible female, but provided only olfactory exposure to her.

\section{EXPERIMENT 1}

\begin{abstract}
Subjects
Method

The animals were 93 male and 30 female rats of the LongEvans strain. The experimentally naive animals were approximately 100 days old at the beginning of experimentation. The males were individually housed, except for a 2 -week period following testing for aggressiveness when each of the $\mathbf{4 0}$ most aggressive males was housed with two females. Those females were then returned to the breeding colony. The 30 naive experimental females were housed five per cage. The rats were in a temperature-controlled $\left(20^{\circ}-22^{\circ} \mathrm{C}\right)$ room with a $12 / 12$-h day-night cycle. Food and water were freely available to the animals at all times.
\end{abstract}

\footnotetext{
Apparatus

A slightly modified version of an apparatus constructed for the earlier research was used. A detailed description and a diagram of the apparatus are available in Taylor (1975). The apparatus is composed of two wood and Plexiglas structures that face each other. One of the structures is a small, gray compartment, $11 \times 14 \times 30 \mathrm{~cm}$, that houses the male subject when he is being exposed to the female. A guillotine door prevents him from entering the second, and larger $(62 \times 22 \times 30 \mathrm{~cm})$, structure.

The second structure is manually movable along tracks and is composed of four compartments. At one end of the structure is a gray compartment used to house the female. A permanently attached screen of 1.26-cm hardware cloth covers the front of the female's compartment. An empty unpainted compartment that serves as an olfactory "dead space" is located next to the female compartment. The other two compartments are for a submissive target male. One compartment is painted black and the other white.
} 
To facilitate the air flow from the female to the male, holes were drilled in the rear base of the compartment that housed the female. A small electric exhaust fan was attached to the rear base of the male subject's compartment, and it was in operation at all times during the experiment. Before the day's experimental session, a visible smoke was used as a test to ensure that the air was flowing easily and in the proper direction.

The guillotine door on the male subject's compartment was opaque, yet the door allowed air to be easily drawn from the female's compartment. This was accomplished by drilling holes in the two pieces of Masonite, then fitting them together to form the door so that there was a space between the two Masonite pieces, and the holes were offset from each other. Finally, a white noise was used to mask auditory cues when the "olfactory" males were being tested.

\section{Procedure}

Pretraining.The male rats were initially tested for relative aggressiveness in a neutral cage, $50 \times 27 \times 22 \mathrm{~cm}$. The males were paired once each day in round-robin fashion and observed for $5 \mathrm{~min}$. The aggressive behaviors recorded were adapted from those described by Grant (1963). The behavioral categories were threats, pushing, crawling over/under, aggressive grooms, aggressive postures, boxing, and attacks with biting. Of the 93 males, the 40 most aggressive rats were selected to be the experimental subjects. The subjects were assigned randomly to one of four conditions, 10 males in each condition. The $\mathbf{2 0}$ least aggressive males were retained as target animals, and the remaining 33 males were discarded from the experiment. The experiment began after a 2-week period during which the experimental subjects were housed with females.

Experimental training. Stage $1-$ In the first of three stages, all four groups of aggressive subjects were exposed to an inaccessible diestrous female. Vaginal smears were used to establish the estrous cycle of the female. Following each exposure to the female, the males were given one of four spaced trials each day to an empty compartment or a compartment housing one of the subordinate target males. The intertrial interval was approximately $5 \mathrm{~min}$. These trials consisted to two initial free-choice trials where the animals could choose either compartment. The third and fourth trials were forced-choice trials in that the subjects were forced to the side opposite to that chosen on the free trials. This procedure guaranteed that the subject confronted the stimulus male on two, but only two, trials each day. The male subject never experienced the same female or the same target male twice on the same day.

During the first stage, the only difference among the four groups was the type of exposure to the female. A procedure developed for the earlier research (Taylor, 1975) was used to expose the males in Groups 1 and 3 to the female. The guillotine door was raised and the only barrier to the female was the wire mesh screen. For the rats in Groups 2 and 4, however, the opaque guillotine door remained lowered and white noise was presented. The principal exposure to the female was by the air flow (cf. Carr, Loeb, \& Dissinger, 1965; Ropartz, 1968).

A trial began by positioning the female compartment in front of the compartment housing the male subject. After a 1-min exposure, the guillotine door was lowered for the males in Groups 1 and 3 (the door, of course was already closed for the animals in Groups 2 and 4). The larger structure was then moved manually until the male subject was in a position facing the black and/or white compartments. On free-choice trials, the black and white compartments were situated so that the aggressive subject could veiw and had access to both compartments. During forced-choice trials, either the black or the white compartment was placed directly in front of the subject and the male could enter only that compartment.

A submissive target male was always in either the black or the white compartment and the other compartment was empty. The target rat was in the black compartment for half the subjects in each group and in the white compartment for the other half. If the aggressive subject entered the compartment housing the target male, the animals were observed for $1 \mathrm{~min}$ and the aggressive behaviors were recorded. If the compartment chosen was empty the subject remained there for the $1 \mathrm{~min}$ and then was removed. Each compartment was cleaned after each subject's daily trials.

The purpose of Stage 1 was to allow the subjects to learn to discriminate between the black and white compartments. It was also used to establish baselines for choosing the target males on the free-choice trials and for aggressiveness when in the presence of the stimulus male. The subjects received 40 trials, 20 trials to each of the compartments.

Stage 2-During the second stage, the male subjects in the experimental groups (Groups 1 and 2) were exposed to an inaccessible estrous female. The males in the control groups (Groups 3 and 4) continued to be exposed to a diestrous female. As in Stage 1 , the males in Groups 1 and 3 received multisensory exposure to the female and the males in Groups 2 and 4 received exposure through olfaction.

Once again, the subjects received 40 trials. The purpose of the second stage was to examine the effects of an estrous female on subsequent free-choice behaviors and on fighting by the aggressive subjects.

Stage 3-To examine the effects of reexposure to a diestrous female, the subjects during the third stage were treated exactly as they were during Stage 1 . The animals received 40 free and forcedchoice trials following exposure to a diestrous female.

\section{Choice Behaviors}

\section{Results}

The two daily free choice trials examined the animals' preferences for interacting with a target male. Figure 1 presents the percentage of choices made by subjects for target males. A $2 \times 2 \times 15$ factorial analysis of variance was performed on the arcsin transformed percentage of choices for the submissive target males. The main factors were female exposure (estrus or diestrus), sensory exposure (multisensory or olfaction), and blocks of 2 days. The results revealed significant interaction only for the female exposure factor over days $[F(14,504)=7.92, p<.01]$.

Analyses of simple main effects of the interaction (Kirk, 1968, p. 283) indicated that the males exposed to an estrous female (Groups 1 and 2) made more

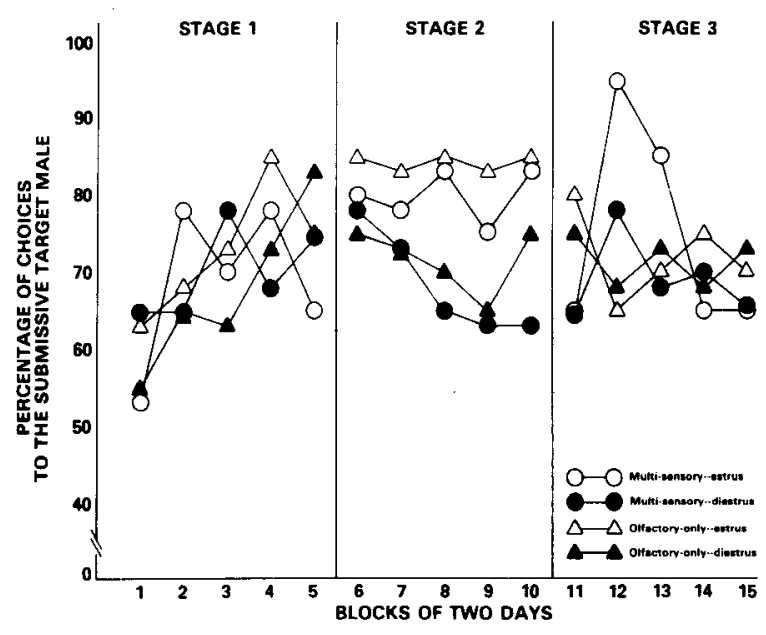

Figure 1. The percentage of choices by the aggressive males to their respective target males (Experiment 1). Estrous exposure refers only to Stage 2 . 
choices of the target males on blocks of Days 8-10 than did the diestrous-exposed control males [ranges of $\mathrm{F}(1,36)$ values $=4.45-5.80, \mathrm{p}<.05]$. A withingroups comparison revealed that only the estrusexposed males significantly altered their patterns of choices over days $[F(14,504)=2.18, p<.05]$. The subsequent comparisons of mean performance difference used the Scheffe method ( $p<.05)$. The results indicated that the experimental males made more choices of target males during Stage 2 than during the final two blocks of days during Stage 1.

\section{Aggressive Behaviors}

With the free-forced choice procedure, the subjects confronted the target males twice, and only twice, each day. A daily mean number of aggressive behaviors (Taylor, 1976) was calculated for the animals in each group, and the results appear in Figure 2 . A $2 \times 2 \times 15$ factorial analysis, with the same main effects as the choice behaviors, was performed on the aggressive responses. The results revealed a significant triple interaction $[F(14,504)=3.07, p<.01]$.

Further analysis indicated that there was a significant simple interaction effect of female exposure (estrus or diestrus) by blocks of days for the multisensory groups $[F(14,504)=11.23, p<.01]$ and for the olfaction groups $[F(14,504)=14.11, p<.01]$. The multisensory animals exposed to an estrous female (Group 1) were more aggressive than the multisensory animals exposed only to a diestrous female (Group 3) on blocks of Days 6-11 [range of $F s(1,36)=4.96-35.25, \mathrm{p}<.05$ ] Also, in the olfaction groups, the estrous-exposed males (Group 2) were more aggressive than their diestrus-exposed control males (Group 4) on blocks of Days 6 and 8-10 [range of $F s(1,36)=5.20-8.68$, $\mathrm{p}<.05]$.

In addition, the simple interaction effect of Sensory Exposure (multisensory or olfaction) by Blocks of

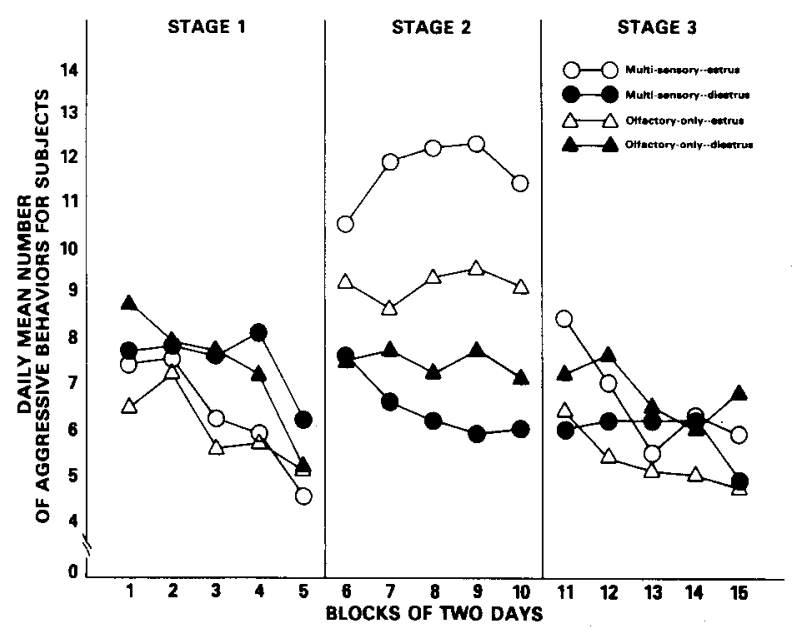

Figure 2. The individual daily mean number of agonistic behaviors initiated by the aggressive subjects in interaction with their respective submissive target males (Experiment 1).
Days of Training was significant, $[F(14,504)=9.69$, $\mathrm{p}<.01$ ], but only for the estrus-exposed males. The multisensory males were more aggressive than the olfaction males on blocks of Days 7-10 [range of F's $(1,36)=4.96-8.81, p<.05]$. The control groups exposed only to diestrous females did not significantly differ.

Finally, within-group analysis demonstrated that the pattern of agonistic behaviors of both groups of males exposed to an estrous female (Groups 1 and 2) changed over days $[F(14,504)=26.52, p<.01$, and $F(14,504)=13.40, p<.01$, respectively]. A post hoc examination with the Scheffé method $(p<.05)$ was used to compare mean performance of the final two blocks of days of Stage 1 with the means during the various days of Stages 2 and 3 . For Group 1, the males were more aggressive on blocks of Days 6-11 than they were during the latter days of Stage 1. Groups 2 was similarly more aggressive after exposure to an estrous female, though for only blocks of Days 6-10.

\section{EXPERIMENT 2}

The data from the first experiment suggest that exposure to an inaccessible estrous female via multiple senses is more effective in increasing male hostilities than is exposure by olfaction. There is, however, a potentially confounding variable in the experiment. Recent data suggest that female rodents may use ultrasounds to communicate information about their estrous cycles (Floody, Pfaff, \& Lewis, 1977; Geyer \& Barfield, 1978). The noise generator that was used in Experiment 1 to block auditory cues in the "olfaction" groups emits frequencies to a maximum of $15-20 \mathrm{kHz}$. Rodent ultrasounds may be as high as $70 \mathrm{kHz}$ (McIntosh, Barfield, \& Geyer, 1978; Nyby, Dizinno, \& Whitney, 1976).

It is possible that the olfaction condition was, in fact, olfaction plus ultrasounds. Previous experiments with the present paradigm led me to doubt that ultrasounds from the female increase the males aggressiveness. The target male is in reasonably close proximity to the female and, presumably, within hearing range; yet, he never exhibited the aroused state that is characteristic of the estrus-exposed subject male. A second experiment, in which some males were exposed only to the soiled bedding of females, was performed to examine the effects of female ultrasonics in the paradigm.

\section{Subjects}

\section{Method}

The animals were 72 male and 20 female Long-Evans hooded rats. The experimentally naive animals were approximately 100 days old at the beginning of experimentation. They were housed and maintained identically to the rats of Experiment 1.

\section{Apparatus}

The apparatus was the same as that used in the first experiment. 


\section{Procedure}

As in Experiment 1, the males were tested initially for relative aggressiveness in a neutral observation cage. The 30 most aggressive males were selected as the experimental subjects, the 20 least aggressive rats were retained as target animals, and the other 22 males were discarded from the experiment. Each of the aggressive subjects was then housed with two females for 2 weeks.

The experimental design for the second study was different from that used in Experiment 1. It was a completely between-subjects design, with each subject male being exposed to a single condition throughout the experiment. The design offered a test that it was the change in exposure, rather than the presence of the estrous female, which accounts for the results of Experiment 1.

The 30 experimental subjects were assigned to one of five groups, six males per group. Twelve of the animals were treated identically to the "olfaction" rats of the first study. Those males were exposed either to an estrous female (Group 1) or a diestrous female (Group 3) by means of a closed door through which air could circulate. The remaining 18 male subjects were exposed only to the soiled bedding of an estrous female (Group 2), only to a diestrous female (Group 4), or only to clean bedding (Group 5). To obtain the soiled bedding, a female was examined for her stage of estrus. If appropriate, she was placed in the "female compartment" for $1 \mathrm{~h}$ and then removed before the males were introduced into the apparatus.

The males were given four trials per day, two free and two forced, for 20 days. One of the target males was always in one goal area and the other goal area was empty.

\section{Results}

The null hypothesis examined in the second experiment was that the responses of the males would not differ whether the female was physically present, though blocked from the view of the male, or only her soiled bedding was present. The suggestion was that ultrasonic auditory cues from the female would not provoke additional changes in the male's behavior.

\section{Choice Behavior}

The percentage of choices by the aggressive experimental subjects to the submissive target males was calculated, and the results appear in Table 1 . A 5 by 10 factorial analysis of variance was performed on the arcsin transformed percentage of choices, with the main factors of type of female exposure and blocks of 2 days. The results revealed no significant differences with either of the factors, though the inter-

Table 1

Percentage of Choices to the Target Male

\begin{tabular}{cccccc}
\hline & \multicolumn{5}{c}{ Female Exposure } \\
\cline { 2 - 6 } $\begin{array}{c}\text { Blocks of } \\
\text { 2 Days }\end{array}$ & Estrus & $\begin{array}{c}\text { Estrus- } \\
\text { Bedding }\end{array}$ & Diestrus & $\begin{array}{c}\text { Diestrus- } \\
\text { Bedding }\end{array}$ & $\begin{array}{c}\text { Clean } \\
\text { Bedding }\end{array}$ \\
\hline 1 & 42 & 54 & 46 & 58 & 50 \\
2 & 63 & 58 & 42 & 50 & 46 \\
3 & 67 & 54 & 58 & 54 & 54 \\
4 & 58 & 67 & 54 & 63 & 58 \\
5 & 84 & 76 & 67 & 63 & 71 \\
6 & 84 & 80 & 76 & 76 & 71 \\
7 & 76 & 80 & 76 & 71 & 71 \\
8 & 89 & 76 & 89 & 84 & 89 \\
9 & 89 & 84 & 80 & 93 & 89 \\
10 & 89 & 93 & 84 & 89 & 84 \\
\hline
\end{tabular}

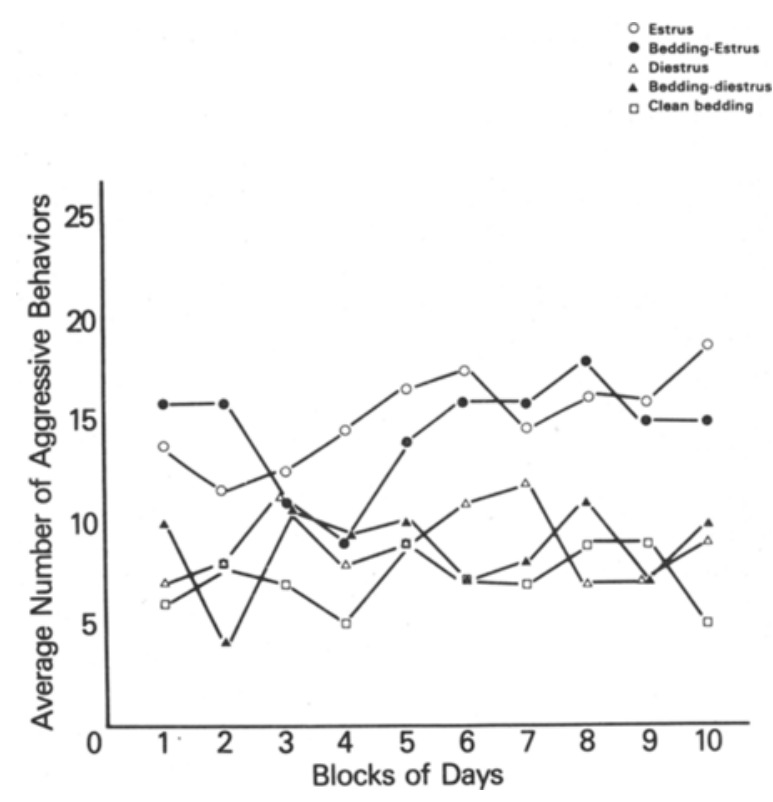

Figure 3. The individual daily mean number of agonistic behaviors initiated by the aggressive males with the submissive target males (Experiment 2).

action approached significance $[\mathrm{F}(36,250)=1.42$, $\mathrm{p}<.10]$

\section{Aggressive Behaviors}

A daily mean number of agonistic behavior was obtained for the animals in each of the five groups. The results appear in Figure 3. A 5 by 10 factorial analysis was performed on the data, with type of female exposure and blocks of days as the main factors. The interaction was significant $[F(36,250)=6.38$, $\mathrm{p}<.01]$.

Analyses of simple main effects of the interaction revealed that the various groups differed on every block of days except for blocks of Days 3-4 [range of $\mathrm{F}(4,250)$ values was 2.71-4.60]. A posteriori comparisons (Tukey's HSD, $\mathrm{p}<.05$ ) revealed that only the estrous-female-exposed males differed from the other groups. Though the two groups of estrous-femaleexposed males differed early in the experiment, the differences were not consistent. Males that were exposed to the bedding of the estrous female (Group 2) were more aggressive than the males in the olfactory group (Group 1) on blocks of Days 1-2, but were less aggressive on blocks of Days 4-5. The animals in those two groups behaved similarly on all other blocks of days.

\section{DISCUSSION}

The mere presence of a sexually receptive female can have profound physiological and behavioral effects on male rats. The male may experience elevated levels of circulating testosterone (Kamel, Mock, 
Wright, \& Frankel,1975) and heightened levels of activity (Purvis \& Haynes, 1974; Slonaker, 1935). The present data suggest that the males also become more aggressive (see, also, Barnett, Evans, \& Stoddart, 1968; Flannelly \& Lore, 1977; Taylor, 1975) and that the odor of the estrous female is capable of increasing intermale conflict.

In Experiment 1, some males were presented first with an inaccessible diestrous female and then with an inaccessible estrous female. Control males were exposed to an inaccessible diestrous female throughout the experiment. The males were more aggressive, and were more likely to interact with a same-sex conspecific, following exposure to the estrous female.

These data were essentially confirmed in Experiment 2. To prevent ultrasonic communication between the female and the male, some males were exposed only to the soiled bedding of the female. The males in the bedding conditions did not differ from their respective control males, which were exposed to the female via an airflow through an opaque door. The males exposed to the bedding from an estrous female were more aggressive than the males exposed to the bedding from a diestrous female or to clean bedding. These findings suggest that a sex pheromone can also act as an aggression-inducing pheromone.

Multisensory exposure to the estrous female was more effective in provoking intermale fighting than a more limited, olfaction exposure. If the increased aggressiveness was mediated purely by a sex pheromone, the males limited to olfactory exposure should have been comparably affected by the presence of an estrous female. Of the males exposed to an estrous female in Experiment 1, the olfaction rats were notably less aggressive than the multisensory rats. I conclude that olfaction is sufficient to increase the males aggressiveness following exposure to an estrous female, but that additional sensory modalities are necessary to produce the full effect.

Since it has been suggested that nocturnal mammals rely heavily on olfaction for social communication (Bronson, 1971; Shorey, 1976), these findings may be surprising. It seems that the rat is not solely dependent upon olfaction to obtain information about its environment (Alberts \& Galef, 1973; Cowan, 1976). In the context of another social behavior, sexual responses, the male rat's copulatory abilities were not eliminated with anosmia (Beach, 1947; Bermant \& Taylor, 1969; Larsson, 1975). Thor and Flannelly (1978) reported that anosmic rats could find the estrous females in a social group. They suggested that the female's movements provided the cue for the male. In the present investigation, the increased activity of the female in estrus (Barnett, 1975, p. 146) may have provided visual cues for the male.

The results offer additional support for the suggestion that the males are more aggressive following exposure to a sexually receptive female. Olfaction play an important role in mediating the increased aggressiveness. Multisensory exposure to an estrous female is even more effective in provoking conflict among males.

\section{REFERENCES}

Alberts, J. R., \& Galef, B. F. Olfautory cues and movement: Stimuli mediating intraspecific aggrenion in the wild Norway rat. Journal of Comparative and Phvsiological Psychology, $1973,85,233-242$.

BarnetT, S. A. The rat: A study in behaviour (2nd ed.) Chicago: University of Chicago Press, 1975

Barnett, S. A., Evans, C. S., \& Stombart, R. C. Influence of females on conflict among wild rats. Journal of Zoology, 1968, 154, 391-396.

BeAch, F. A. A review of physiological and psychological studies of sexual behavior in mammals. Physiological Review, 1947, 27, 240-307.

Bermant, G., \& Davidson, J. M. Biological bases of sexual behavior. New York: Harper \& Row, 1974.

Bermant, G., \& TAylor, L. Interactive effects of experience and olfactory bulb lesions in male rat copulation. Physiology \& Behavior, 1969, 4, 13-17

Bronson, F. H. Rodent pheromones. Biology of Reproduction, 1971, 4, 344-357.

Carr, W. J., Loeb, L. S., \& Dissinger, M. L. Responses of rats to sex odors. Journal of Comparative \& Physiological Psychology, 1965, 59, 370-377.

Cow an, P. E. The new object reaction of Rattus rattus L: The relative importance of various cues. Behavioral Biology, 1976, 16, 31-44.

Flannelly, K., \& Lore, R. The influence of females upon aggression in domesticated male rats (Rattus norvegicus). Animal Behaviour, 1977, 25, 654-659.

Floody, O. R., Pfaff, D. W., \& Lewis, C. D. Communication among hamsters by high-frequency acoustic signals: II. Determinants of calling by females and males. Journal of Comparative \& Physiological Psychology, 1977, 91, 807-819.

GEYER, L. A., \& BARFIELD, R. J. Influence of gonadal hormones and sexual behavior on ultrasonic vocalizations in rats: 1 . Treatment of males. Journal of Comparative \& Physiological Psychology, 1978, 92, 447-456.

Grant, E. C. An analysis of the social behaviour of the male laboratory rat. Behaviour, 1963, 21, 260-281.

GuHı, A. M. Gonadal hormones and social behavior in infrahuman vertebrates. In W. C. Young (Ed.), Sex and internal secretions (Vol. 2). Baltimore: Williams and Wilkins, 1961.

Healey, M. C. Aggression and self-regulation of population size in deermice. Ecology, 1967, 48, 377-392.

Kamel, F., Mock, E. J., Wright, W. W., \& Frankel, A. I. Alterations in plasma concentrations of testosterone, $\mathrm{L} \mathrm{H}$, and prolactin associated with mating in the male rat. Hormones \& Behavior, 1975, 6, 277-288.

KIRK, R. E. Experimental design: Procedures for the behavioral sciences. Belmont, Calif: Brooks/Cole, 1968.

LARSSON, K. Sexual impairment of inexperienced male rats following pre and post puberal olfactory bulbectomy. Physiology \& Behavior, 1975, 14, 195-199.

McIntosh, T. K., Barfield, R. J., \& Geyer, L. A. Ultrasonic vocalisations facilitate sexual behaviour of male rats. Nature, 1978, 272, 163-164.

Nyby, J., Dizinnio, G. A., \& Whitney, G. Social status and ultrasonic vocalizations of male mice. Behavioral Biology, 1976, 18, 285-289.

Punvis, K., \& Haynes, N. B. Short-term effects of copulation, human chorionic gonadotrophin injection, and non-tactile association with a female on testosterone levels in the male rat. Journal of Endocrinology, 1974, 60, 429-439. 
ROPARTz, P. The relation between olfactory stimulation and aggressive behavior in mice. Animal Behaviour, 1968, 16, 97-100.

Roper, T. J., \& Polioudakis, E. The behavior of Mongolian gerbils in a semi-natural environment, with special reference to ventral marking, dominance, and sociability. Behaviour, 1977, 61, 207-237.

SADLEIR, R. M. F. S. The relationship between agonistic behaviour and population changes in the deermouse, Peromyscus maniculatus. Journal of Animal Ecology, 1965, 34, 331-352.

Shorey, H. H. Animal communication by pheromones. New York: Academic Press, 1976.

Slonaker, J. R. Sex-drive in rats. American Journal of Physiology, 1935, 112, 176-181.

Stehn, R. A., Richmond, M. E., \& Kollisch, N. Female odors and aggression among male Microtus. Behavioral Biology, 1976, 17, 43-50.

TAYLOR, G. T. Male aggression in the presence of an estrous female. Journal of Comparative \& Physiological Psychology, $1975,89,246-252$.

TAYLOR, G. T. Influence of female's sexual cycle on aggressiveness in male rats. Journal of Comparative \& Physiological Psychology, 1976, 90, 740-746.

Thor, D. H., \& Flannelly, K. J. Sex-eliciting behavior of the female rat: Discrimination of receptivity by anosmic and intact males. Behavioral Biology, 1978, 23, 326-340.

Turner, B. N., \& Iverson, S. L. The annual cycle of aggression in Microtus pennsylvanicus and its relation to population parameters. Ecology, 1973, 54, 967-981.

Wilson, A. P., \& Boelkins, C. Evidence of seasonal variation in aggressive behavior by Macaca mulatta. Animal Behaviour, $1970,18,719-724$.

(Received for publication November 6, 1978; revision accepted December $27,1979$. 